\title{
Tobacco Control at Community Colleges: Context and Opportunities
}

\author{
Scott Mclntosh ${ }^{1}$, Andrew F. Woll ${ }^{2}$, Tye Johnson ${ }^{I}$, Douglas H. Done ${ }^{3}$, Jordan H. \\ Kurtzman ${ }^{I}$, Duncan Ververs ${ }^{l}$, Deborah J. Ossip ${ }^{I}$
}

\begin{abstract}
INTRODUction Tobacco use among United States college-aged students remains higher than that of the national average. While a majority of public health literature has explained tobacco control programs and policies at traditional four-year colleges and universities, little research exists on programs and policies at two-year community colleges. It is important to understand such efforts at these institutions as they have vastly different infrastructures and enroll a more diverse and at-risk student body compared to traditional four-year colleges.

METHODS The role of community colleges in health efforts aimed at tobacco use was examined at four community colleges. Qualitative research methods included 18 interviews and four focus groups $(\mathrm{N}=55)$, document review, and direct environmental observation.

RESULTS Community colleges offered a limited number of tobacco cessation and secondhand smoke prevention initiatives. All colleges provided tobacco control literature, though additional programming varied by college. Indoor and outdoor tobacco use policies existed on all campuses though enforcement was problematic. Little evidence was found that current program and policy approaches are based upon best practices or are being employed successfully.

conclusions Opportunities for best practice strategies for tobacco control were identified for community colleges, and would require little additional infrastructure. Policy adherence and enforcement could be improved with awareness raising with students, faculty and staff. Cessation tools for students must be convenient, understandable, and accessible from multiple locations. Feasible approaches for future initiatives could include testing low cost technology such as quitlines, Web Assisted Tobacco Interventions (WATI) and outside partnerships with community organizations and health agencies.
\end{abstract}

\section{AFFILIATION \\ 1 University of Rochester Medical Center, New York, USA 2 University of Redlands School of Education, Redlands, USA 3 University at Albany School of Public Health, Department of Epidemiology and Biostatistics, Rensselaer, New York, USA \\ CORRESPONDENCE TO \\ Dr. Scott McIntosh, University of Rochester Medical Center, 265 Crittenden Blvd, CU 420644, 14642 Rochester, United States. Email: scott mcintosh@urmc.rochester.edu}

\section{KEYWORDS}

health policy, young adults, qualitative, tobacco cessation

\section{INTRODUCTION}

College environments are important sites for health interventions. Each year, colleges enroll a large number of students with diverse backgrounds. In 2012, it was estimated that 21.6 million people will have attended a college or a university in the United States ${ }^{1}$. As students transition to college, they often engage in a variety of adverse health behaviors ${ }^{2}$. One of the most serious health concerns on college campuses is tobacco use $^{3-4}$. The estimated prevalence of smoking amongst college students varies widely, with estimates as high as $28.4 \%$ exceeding that of the adult national average (16-19\%) by approximately $47 \%{ }^{4-5}$. In various studies, the prevalence of cigarette smoking is higher among community college students than it is among 4-year college students ${ }^{2,6,7}$.
During college, students often begin or continue to smoke as a means to control stress and depression ${ }^{8,9,10}$. As part of a national effort to reduce the toll of tobacco use ${ }^{11}$, the CDC's Healthy People 2020 objectives seek to increase the proportion of college and university students who receive information from their institution on tobacco use from $35.9 \%$ to $36.7 \%$ by $2020^{12}$. In 2011, the American College Health Association recommended that all colleges and universities establish and enforce $100 \%$ indoor and outdoor, campus-wide tobacco-free policies $^{13}$.

When public health officials study smoking at colleges, they often describe colleges monolithically ${ }^{14}$. However, there are many types of colleges in the United States with concomitant variations in student characteristics and related institutional 
policies ${ }^{15,16}$. Nearly half (42\%) of all college students attend two-year community colleges ${ }^{17}$. During the 2013-2014 academic year, the total number of undergraduate enrollees at 2-year institutions in the US was approximately 7 million, and by 2024 enrollment at 2-year institutions is expected to increase by 15 percent, to 8 million students.

Specifically of interest here, aggregating college students into a single population of study fails to recognize the vast differences between four-year college students and two-year community college students ${ }^{16}$. While the majority of students at both types of colleges are enrolled upon graduating high school and represent a wide variety of races and ethnicities, community colleges enroll a larger number and higher percentage of students with minority statuses, and those from non-traditional college age groups such as veterans and midlife and older persons ${ }^{18}$. Community colleges systematically attract a different group of learners than traditional four-year institutions by offering open admissions, lower tuitions, skill training curriculums, and adult education programs ${ }^{14,15}$. With the recent economic downturn, community colleges have become more appealing options for both young students, who desire to complete general coursework before attending a more costly four-year college, veterans returning from active duty, and returning students who must increase their qualifications as the job market tightens ${ }^{15}$.

In general, despite the growing community college population, research addressing this diverse student body remains limited ${ }^{16}$. Similarly, most of the research on college tobacco use has focused on traditional four-year colleges and universities ${ }^{19}$. However, from a health perspective, community colleges have a higher at-risk population compared to fouryear colleges ${ }^{14,} 18-19$. The limited literature on community college students indicates that, compared to traditional fouryear students, community college students are more likely to smoke, to describe themselves as regular smokers, and to fail at quitting ${ }^{20-21}$. Community college students are less concerned about tobacco related health consequences than four-year students and are less supportive of policies that limit tobacco use $^{22}$. Of community college smokers, $45 \%$ state that quitting smoking would have no impact or only a minor impact on their health ${ }^{23}$. These differences suggest a need to develop customized public health tobacco cessation interventions for community college students.

Although community college campuses are settings where the provision of tobacco control resources appears to be feasible, more than half $(58 \%)$ of two-year community colleges lack student health centers ${ }^{24}$. There is limited research on tobacco cessation interventions in this population ${ }^{25-26}$. The present study explored the role of community colleges in tobacco prevention and cessation interventions and secondhand smoke prevention initiatives. This paper describes qualitative results examining tobacco control resources, initiatives and policies at four community colleges in Western New York. The implications of these results for designing future programs and implementing policies at community colleges are discussed.

\section{METHODS}

In order to examine tobacco control resources within the context of health promotion at community colleges, an iterative progressive qualitative research study was conducted with four Western New York community colleges. All four community colleges, which were selected for proximity (within 30 miles of the parent study institution), agreed to participate in the study 1) after initially agreeing to provide a letter of support (signed by each institution's president or administrative representative), and 2) again at the time of data collection upon telephone or face-to-face discussion with the Principal Investigator. Purposive sampling was used to obtain geographic diversity; two of the four colleges were located in rural areas, one in a middle class suburb, and the last in an urban environment.

Qualitative methods were established to systematically and iteratively build on qualitative findings from broader environmental observations to semi-structured individual interviews to facilitated focus groups. Methods included document review, direct environmental observation, individual interviews $(n=18)$ and, to ensure equitable campus representation, one focus group at each of the four campus sites $(n=4)^{27}$. Sampling for in-depth individual interviews was also done purposively. Two types of interviews were conducted: key informant interviews (KIIs) with students ( $\mathrm{n}=11$ ), and key opinion leader interviews (KOLs) with faculty and staff $(n=7)$. At least two KIIs were conducted at each of the four sites, and two KOLs were conducted at each site, except one campus for which there was only one KOL.

The approach emphasized an overall, iterative, systematic approach - including the sample size for the individual interviews - which were primarily conducted to be built upon from the previous environmental observations and with the main goal of informing the subsequent focus group procedures, but with acknowledgment that the individual interviews were valuable in their own right. The procedures iteratively build from environmental observations, to strategically including KII and KOL from each campus, followed by the establishment of one contextually informed focus group at each campus. Although only $1 \mathrm{KOL}$ was conducted at one of the sites, this site was a sister site to the same community college, so 
representativeness of that college was considered saturated.

To gain insight and environmental context from the study population's point of view, and to generate preliminary research suppositions prior to development of interview and focus group guides, study personnel conducted an extensive document review and direct environmental observations on each of the four campuses. College brochures, posters, maps, and publications were reviewed, along with tobacco control policies found on the colleges' websites.

Direct environmental observation included onsite observation of student behaviors to better understand the campus environment. Each campus had at least two primary sites. Teams of at least two project staff visited each site with the goal of determining campus layouts (including student residential areas, health offices and other resources, parking, and common student gathering areas), and taking photographs, such as of smoking related signage and designated smoke free areas. The age and racial diversity of the students was also observed during campus visits. Each visit was supplemented by field notes to track researcher observations of the environment, including where students smoked and evidence of smoking, such as cigarette butts.

To facilitate the recruitment of at least one key opinion leader from each campus and at least two students from each campus, a minimum of two on-site visits to each of the four campuses was supplemented with advanced engagement with on-site champions (previously identified campus staff in support of the study, as well as those newly identified per the environmental observational efforts), including their assistance in posting IRB-approved flyers and sending email recruitment letters to potential participants.

The KII and KOL interviews followed the study protocol's systematic strategy to engage with champions and students from across all four campuses. A small strategic sampling strategy was conducted to ensure representative key informant qualitative information from each campus. The goals were to 1) iteratively build on environmental observations to further refine the subsequent focus group procedures (interview guides and recruitment), and 2) examine qualitative data at the individual level.

Semi-structured KII/KOL interview guides were developed to facilitate consistent interviews. Domains included questions regarding tobacco cessation strategies, tobacco control policies, and tobacco use as a problem on campus. All interview participants were introduced to the project prior to beginning the interview to maximize comprehension of the study and to facilitate informative answers. Each participant was consented and interviewed by two researchers experienced in qualitative interviewing methods: one who led the interview and the other who added additional questions, recorded the interviews, and took notes.

With the goal of interviewing a diverse group of community college students, $11 \mathrm{KII}$ interviews were conducted with young adult students $(n=6)$, returning students $(n=3)$ and veterans $(n=2)$. Seven KOL interviews sampled a variety of information rich school officials including directors of student health centers, administrators, educators, an associate dean, and a director of residential life.

Four focus groups were conducted with 8-12 diverse students each (total $n=41$ ) and addressed similar topics as those in individual interviews. Five of the students in the focus groups had previously participated in KII interviews. One focus group consisted of students who lived on-campus as it was hypothesized that this group may offer a unique perspective on tobacco use patterns at community colleges. Data collection was iterative - environmental observation and individual interview responses and preliminary data analysis were used to shape the focus group protocols. All focus groups and interviews were tape recorded.

Study protocols were approved by the authors' institution's IRB, and informed consent was obtained from all individual participants included in the study. Monetary incentives were provided to participants: $\$ 15$ for $\mathrm{KII} / \mathrm{KOL}$ interviews, and $\$ 25$ for focus group participation.

\section{Statistical Analysis}

All interviews and focus groups were recorded and transcribed verbatim by the study team ${ }^{27}$. Following transcription, the study team engaged in open and then axial coding of each transcript. During open coding, initial codes were developed that defined, labeled, and promoted inclusivity of interview data. After establishing a broad framework for data analysis, axial coding (a structured process to associate self-reported constructs) led to developing more specific categories and subcategories $^{28}$. Weekly meetings were held to debrief and compare emerging data patterns to solidify codes. Following code creation, quotations of text with codes were placed in a spreadsheet to aid in analysis. Data were stored, sorted and reviewed by the study team during debriefing meetings. Two coders independently coded quotations of text per numbered themes as these domain-based themes emerged from the data (e.g., existence of tobacco-related literature on a given campus).

After coding, review, and regular peer debriefing, themes from interviews and focus groups emerged ${ }^{29}$. These findings were triangulated with data obtained from participant 
observation and document review, utilizing consistent coding categories. The findings were compared among interviews, focus groups, observation, and document review to increase confidence in the trustworthiness of the data.

\section{RESULTS}

Because of the diverse nature of community colleges, student populations were described and reasons for tobacco use during college were identified. This descriptive background constructs a framework for explaining and understanding the role of community colleges in tobacco control efforts.

\section{Community College Setting and Population}

The study sample consisted of 55 students, administrators, and staff members. The student sample $(n=41)$ included those of different race, age, gender, and experiences (traditional students, returning students, and veterans). The sample of key opinion leaders $(n=9)$ interviewed in the seven KOL interviews (note: 2 of the interviews were conducted with two opinion leaders in attendance), consisted of two health center directors, four student service administrators, one residential life director, one educator from the department of nursing, and one associate dean. Most students in this study lived off campus

\section{Table 1. Contextual themes at community colleges}

\begin{tabular}{|c|c|}
\hline Theme & Sample Quotes \\
\hline $\begin{array}{l}\text { Diverse student } \\
\text { population } \\
\text { (quote 1) }\end{array}$ & $\begin{array}{l}\text { There are students right out of high school to } \\
\text { about [age] } 22 \text {. Some of them are taking a break } \\
\text { or some of them are raising families or what have } \\
\text { you. And then I would say there's that 24-25 } \\
\text { year old and above who is your traditional, I } \\
\text { would call adult learner. Um, and then that means } \\
\text { somewhere between } 22 \text { and } 25 \text {, it's a grey zone. } \\
\text { They could be right out of high school or coming } \\
\text { back from the military. They may be considered } \\
\text { more adults whereas some of your students who } \\
\text { just are floundering and god only knows what they } \\
\text { are doing. And I would consider them your more } \\
\text { traditional age cause they have none of those life } \\
\text { skills built up. (Director of Student Life) }\end{array}$ \\
\hline
\end{tabular}

Stress as a reason to smoke (quote 2)
Socializing as a reason to smoke (quote 3)
Yeah, I mean I came to college you know my Dad smoked growing up. I always told myself I wouldn't smoke, my sister did the same thing, but me and my sister both smoke. Come to college, whole new ballgame, with the stresses and you know cigarettes kind of help. I think I picked it up within a month of being at college...Maybe when I'll get out of college, when I have less stress, I mean when you get out of college it's a whole new ballgame, the stresses will stop (Male, Traditional Student)

You definitely meet new people, you kind of like branch out you kind of, you definitely meet people, kind of socialize, a lot of socializing...we've met a lot of friends at this smoking booth. (Male, Traditional Student) and commuted daily to attend class. Students had a variety of life experiences before matriculating at their respective colleges including military combat, previous employment, drug and alcohol rehabilitation, and even homelessness. Several students not only had the responsibility of attending class, but had additional responsibilities such as full-time work and parenting. The Director of Student Life at one community college described the diversity of this population using several categories including age and reason for attending community college (Table 1, quote 1). The majority of students who utilized student lounges and hangouts appeared to be traditional college-aged rather than older adult learners.

\section{Reasons for Tobacco Use Include Stress and Socializing with Peers}

The community college students often described tobacco use as a means to reduce stress. Most who began using tobacco in college stated they would quit upon graduating as they believed their stress level would dramatically fall at that time. One student described his smoking behavior as a function of both stress and family relationships (Table 1, quote 2). Smoking at community colleges was also a facilitator of socializing. Students stated they smoked between classes and identified friends as fellow smokers. Groups of smokers huddled together talking were observed on multiple occasions. One student described smoking at campus smoking huts as a facilitator of relationship formation (Table 1, quote 3).

\section{Community College Tobacco Control Efforts}

The qualitative findings were classified into two domains: educational programming and policy. Below, eight major themes are organized under these two domains.

\section{Programs and Educational Efforts}

Tobacco use prevention and cessation literature is widely available at community colleges

All four community colleges provided some form of tobacco use prevention and cessation literature. This literature consisted of pamphlets, brochures, posters, and flyers and was typically located outside of wellness or health offices. A majority of the literature addressed the health consequences of tobacco use and social smoking rather than recommending strategies for quitting. Despite the availability of these materials, it was observed that two of the four health centers were located in back hallways that seemed to have little student traffic. At other colleges, health offices made available such materials throughout campus including student lounges and on bulletin boards. One student thoroughly described the availability of 


\section{Research Paper}

\section{Table 2. Themes reflecting community college smoking education efforts and programs}

$\begin{array}{ll}\text { Theme } & \text { Sample Quotes } \\ \text { (quailability of smoking literature } & \begin{array}{l}\text { There's the pamphlets that the student health puts out, there's a display rack right outside this office, } \\ \text { there's posters throughout the school. Every semester they're refreshed put in new locations about the } \\ \text { percentage of students that choose not to smoke, the percentage of students that are making healthy } \\ \text { situations, um, so that it's right there you can walk through the school without noticing something } \\ \text { about the students that don't smoke and that, that are making healthy choices and that you can go to } \\ \text { wherever it says on the poster to get more information. (Male, Veteran Student) }\end{array}\end{array}$

Students don't read smoking literature (quotes 2-5)
Services vary and depend on staff perception (quotes 6-7)

Positive relationships with health center but don't ask for quit help (quotes 8-9)

Smoking is not a priority to college leaders (quotes 10-11)
There's so many different things up on the walls, it's like most people don't stand there and wait and read all the different flyers. It's like I got class, I got friends, I got things to do. (Male, Traditional Student)

Sometimes I just really don't give two cents to anything that's on the walls. I mean I'm just getting to my class I really don't care. (Male, Traditional Student)

I am not a big electronic person I have only got into it because of schooling other than that at home I could care less. I don't have Internet. I do, because I have to log on to see my classes and assignments, and submit assignments to. (Female, Returning Student)

I was given these three bulletin boards that I can use and at first I thought, "Ugh, bulletin boards! Who reads these days? Who looks at these things?" But what I did was I put little cups with small pieces of paper in them that they could take. (Director of Health Center)

But I don't see it as the numbers are so great that they're, 'Oh my goodness, look at them all out there.' I don't it as a major campus-wide problem but that just may be me because I'm not a smoker and I don't really look at them. (Director of Health Center)

My opinion on smokers, I'm a absolute anti-smoker, I've never smoked a cigarette in my life, but as a health educator, I have a lot of compassion for smokers because, when you think the degree of addiction they go through, that they can't shake this, and they go through all of these health problems that you see, as a nurse. So if a student asked me, I'd certainly try to steer them in the right direction. (Educator, Department of Nursing)

The health center here, I would say [is reliable], yes. They're goal here is to keep students healthy, they're not making money off me coming in here saying I got a cough. (Male, Veteran)

To be honest, I really don't get asked [for quit help]. Students don't come to us asking for that kind of help. Once in a while we find out that someone smokes, we'll be like what, we didn't even know that. (Educator, Department of Nursing)

General [health], general [health], just yeah, and that's a slow approach. But as far as some of our most active efforts are in those areas of violence and recovery. (Student Services Administrator)

One of the activities was simply send me an email engaging them in the technology using their student email. Send an email explaining what grade you'd like in this course and what you plan to do in order to attain that. Following that class, I had a discussion with them about the language that they used. What I call text writing, lower case I's, the difference between $t-0$ and $t-0-0$ and $t-w-0$ because it was apparent in the emails that I received. (Director of Residential Life) tobacco control literature on campus (Table 2, quote 1 ).

\section{Students do not read tobacco control literature}

When students were asked about tobacco control resources available on campus, they most frequently mentioned such literature from the health office. Though students were aware of these materials, most young students stated they never read them (Table 2, quote 2). Students did not want to take the time to read such information especially after attending class and completing assignments (Table 2, quote 3 ).

Adult learners seemed more receptive to health literature. Several adult learners stated they still obtained a majority of their information from non-electronic sources such as brochures and newspapers. Unlike most traditional-aged college students, adult learners did not obtain health information from the internet but only used the internet for academic purposes (Table 2, quote 4). Some college officials were aware of the ineffectiveness of passive materials and tried to adopt more creative strategies to engage students when forced to use traditional promotion methods (Table 2 , quote 5).

\section{Cessation programs and services vary by college and depend on staff perception of tobacco control}

Tobacco cessation programs and services varied by community college. The extent of available resources was dependent on the views and attitudes of the health director and college faculty and staff towards smoking. Officials who were compassionate to smokers and who recognized tobacco use as a problem on campus were more likely to have established resources and aid students in quitting (Table 2, quotes 6 \& 7 ). One Director 
Research Paper

\section{Table 3. Smoking Policies by Community College}

\begin{tabular}{|c|c|c|c|}
\hline College & Indoors & Outdoors & Residential Halls \\
\hline \multirow[t]{2}{*}{1} & \multirow[t]{2}{*}{$\begin{array}{l}\text { Prohibited in all } \\
\text { campus buildings / } \\
\text { facilities }\end{array}$} & $\begin{array}{l}\text { Smoke free perimeter around entire compus } \\
\text { Smoking permitted outside of perimeter (parking lots) }\end{array}$ & $\begin{array}{l}\text { Smoking is prohibited inside of residences } \\
\text { and within the painted smoking border arou } \\
\text { main entrances of apartments }\end{array}$ \\
\hline & & & $\begin{array}{l}\text { Smoking is permitted outside of residence } \\
\text { halls }\end{array}$ \\
\hline 2 & $\begin{array}{l}\text { Prohibited in campus } \\
\text { building }\end{array}$ & Smoke free zones within 15 feet of exterior entrances & College does not offer student housing \\
\hline
\end{tabular}

3 Prohibited in all
campus buildings /
facilities
Designated smoking zone on sidewalk near parking garage at rear of building

Smoking prohibited where parking lots end

(beginning of sidewalk) and boundaries marked by signs that state "No Smoking Beyond This Point"

Cigarette receptacles placed around parking lot boundaries

Smoking permitted in parking lots and outside certain academic buildings. Smoking areas are to have seating for smokers.

Prohibited in all compus buildings / facilities

Cannot carry smoking paraphernalia (cigarettes, lighters, pipes) indoors

\begin{abstract}
Exterior entrances marked as smoke-free zones with blue
\end{abstract} striping on sidewalks.

Smoking permitted in designated areas that are marked with signs

Smoking, must be at least 30 feet or more from the entrance
Smoking is prohibited inside residences and directly outside of external entrances

Smoking is permitted at least 25 feet away from residence halls

Smoking is prohibited inside residences and directly outside of external entrances

Smoking is permitted outside where smoking urns are located

\section{Table 4.Themes reflecting community college smoking policy and policy enforcement}

$\begin{array}{ll}\text { Theme } & \text { Sample Quotes } \\ \text { Colleges are } & \text { When there is smoking, it is right in front of } \\ \text { unable to enforce } & \text { the doors, which makes it, you know, not too } \\ \text { smoking policies } & \begin{array}{l}\text { attractive, or it's inconvenient, you know the smell } \\ \text { (quotes 1-2) } \\ \text { and things like that they have um, this uh common } \\ \text { area where smokers go and again its right in front } \\ \text { of the door and it's just um, a cigarette the ashtray } \\ \text { is there but nobody uses the ashtray. (Female, } \\ \text { Returning Student) }\end{array}\end{array}$

Well the grass, there used to be a blue line up against the grass that, saying you had to be the other side of that blue line before you lit up. And it, it was obeyed for awhile and then people started not obeying it and well, why do I have to if he's not, it eventually just faded away. And if a safety officer happens to be walking through, he'll say yeah, you got to get over there. But like I said there's not enough of the safety officers to patrol the courtyard. (Male, Veteran)

Officials lack of awareness to establish and enforce policies (quotes 3 - 4)
The smokers and the non-smokers are constantly arguing against the other group. And essentially the faculty and staff are fit to be tied, all they can do is wait on regulations. (Director of Health)

As a community college, our sponsor is the county. The SUNY chancellor's recommendations can be interpreted differently by community colleges. Depending on how they're interpreted, we may or may not abide by them. (Director of Health) of Health Services distributed a "Quit-Kit" for students to help them begin their quit attempt: a folder with brochures (such as those from the American Cancer Society) and other self-help and referral information. Some directors steered students towards external resources including the state quitline and community programs (e.g., an established face-to-face treatment program in the local metropolitan area consisting of visits with providers, medication oversight, and extensive follow-up).

\section{Students don't ask community college health centers for quit help}

When students were asked if they knew the director of the student health center, most students stated they were familiar with the director. Some students talked to the nurse and others knew the name of health staff that often sent health related emails to them. Students who used the health center seemed to have a positive relationship with staff. When asked where they obtained reliable sources of health information, many students stated they trusted the health center staff and even favored it over outside healthcare providers (Table 2, quote 8).

Despite this positive relationship, health directors stated students didn't visit the health center for quitting help (Table 2 , quote 9). Because of the low utilization of resources and 
lack of requests for help, community college directors did not coordinate and support on-going campus wide tobacco control efforts. Community colleges often sponsored "oneshot" initiatives such as the American Cancer Society's Great American Smoke Out, the Kick Butts Day campaign against Big Tobacco, and quit smoking tables at health fairs occupied by outside health agencies.

\section{Tobacco control is not a priority to college leaders}

Community college personnel stated they focused on promoting general health and addressed health issues they viewed as more pressing than smoking, such as alcohol abuse, violence, and recovery (Table 2, quote 10). Community college officials faced strict budgets to provide a wide variety of resources to large student bodies. Student directors and educators stated they had to allocate a great amount of resources to teaching basic skills such as how to use and write emails and how to register for courses and submit assignments (Table 2, quote 11). These activities occupied a majority of the faculty's time, not permitting them to focus on broad issues such as improving the health of their student body.

\section{Tobacco Control Policies}

Tobacco control policies exist at all colleges though colleges have different rules for tobacco use outside

All community colleges had written policies that established rules for tobacco use on campus both indoors and outdoors and at college sponsored housing. Table 3 describes these polices at the four community colleges. When comparing institutional policies, all colleges banned smoking inside campus buildings, college owned vehicles, and residence halls though tobacco use regulations outdoors varied. All campuses stated they sought to promote smoke free zones and smoke free facilities due to the known negative consequences of tobacco use and second hand smoke. Tobacco use policies were published on the college's website and in student handbooks. On campus, tobacco use policies were outlined on campus maps and signs and by the demarcation of outdoor boundary lines.

\section{Colleges are unable to enforce tobacco control policies}

Enforcing tobacco use policies was recognized as a common problem by both faculty and students at all colleges. While students and faculty were able to correctly explain campus tobacco policies, they stated their colleagues and peers did not often obey them (Table 4, quote 1). Several members of the research team confirmed this when they visited campuses and observed students smoking directly in front of no-smoking signs and outside of building entrances. They noticed cigarette butts outside of doorways which were inside the no-smoking zone boundaries. At one college observation visit, it was observed that enforcing even indoor policies may be problematic. Upon entering a college residence hall, the vestibule smelled of cigarette smoke. Also during visits, it was observed that environmental determinants, such as ashtrays located inside of no-smoking boundaries, contradicted campus tobacco control rules.

Colleges tried to enforce tobacco control policies by having safety patrols or security officers ask smokers to extinguish their cigarette and move to a permitted smoking zone. Students and college faculty stated that this enforcement strategy was unrealistic as colleges could not hire enough personnel to enforce tobacco use rules (Table 4, quote 2).

\section{College officials are unaware of their role in establishing and enforcing tobacco control policies}

Staff and faculty at community colleges were unaware of requirements and responsibilities to aid the enforcement of tobacco control policies. College staff noticed that enforcement was a problem though did not know if it was appropriate to intervene or address this concern with students. Faculty and staff lacked direction such as specific protocols regarding tobacco use on campus. They did not report clarity from leadership on how they should implement policies or guidelines (Table 4, quote 3). This problem stemmed from the lack of direction leaders had when reviewing broad tobacco control initiatives. The unique position of community colleges in Western New York, which are in financial relationships with their associated counties but operate within a larger state-wide education system often along with having privately owned campus housing, gave those in leadership a perceived leeway on adopting or applying county or state school regulations (Table 4 , quote 4 ).

\section{DISCUSSION}

The community colleges examined in this study lack comprehensive tobacco control strategies, and this study's findings reveal there has historically been little institutional will and effort. There is little evidence that program and policy approaches being employed are successful. In order for public health officials to establish community colleges as settings for successful tobacco control efforts, they must identify and utilize strategies and interventions that address, with limited resources, the unique needs of the community college population. Moreover, community colleges must work to improve the enforcement of existing tobacco control policies. Notable strengths at each campus, which serve as an 
important foundation on which to tailor improvements, were that 1) they had specific articulated tobacco-control policies, 2) students were aware of the polices, 3) there was access to tobacco-related health center resources, and 4) these resources were generally well regarded.

In addition to national initiatives for $100 \%$ smoke-free campuses $^{13}$,important state-wide secular trends were occurring (and continue to occur) regarding policy improvements most notably the State of New York's initiatives related to "tobacco-free campuses". All community colleges in the State of New York are part of the State University of New York (SUNY) system, and efforts to improve policies state-wide have helped raise the awareness of tobacco control issues in the community college campuses participating in this study. Recommendations to strengthen polices (such as to become not just "smoke free", but entirely "tobacco free" - no tobacco product use anywhere on campus), have enjoyed increasing political and populace support, although monetary support for specific infrastructure improvements has not yet been realized. Enforcement of policies, even with current resources, personnel and communication capabilities, can nevertheless build on these secular trends.

A first step toward improving adherence to and enforcement of tobacco control policies can be awareness-raising, such as introducing and explaining policies to current and new students, staff and faculty ${ }^{13}$. Integrating tobacco control policy education and awareness into existing events or programs can be a realistic option for community colleges as this effort will require little additional resources from the college. Additional realistic strategies for instituting and maintaining adherence and enforcement need to be identified.

Future tobacco cessation programs must be convenient and readily accessible to students regardless of location or time of day. Even if community colleges have adequate resources to offer tobacco cessation programs that may be more common at four-year institutions, such as support groups and counseling by healthcare personnel, these programs would likely fail due to the unique community college student lifestyle ${ }^{30}$, where the students often are only on campus when commuting for classes.

Community colleges must also consider students' lack of interest and utilization of tobacco control literature and resources provided by the health center. Moreover, the varying staff perceptions of tobacco use as a problem on campus, the lack of institutional resources available to provide cessation services and enforce tobacco control policies, suggests that community colleges need tobacco control interventions that require little infrastructure. There is some evidence that young adults will use quitlines ${ }^{31,32}$, which are universally available - though their effectiveness in this age group is unclear $^{33}$. Quitlines are nevertheless a free and readily available intervention designed to allow access from persons in lowresource environments like community colleges.

In order for community colleges to engage in meaningful tobacco prevention or cessation efforts, even low-infrastructure strategies with limited human resources can be evidence-based and successful. Consistent with trends in the literature, results from this study suggest that one approach that could address these limits is through the adoption of technology-assisted tobacco intervention. Web Assisted Tobacco Interventions (WATIs) are a form of such technology-assisted approaches that are convenient, cost-effective, and can serve a large number of students with low-infrastructure resources of the community college ${ }^{34-36}$. Support for this approach, which would allow asynchronous access to interactive treatment and peer support, is exemplified by the fact that students and officials reported low utilization of on-site resources, and that this study identified a wide variety of materials (both hard copy and electronic) that could easily add links to evidence-based online resources without the need for any higher-level infrastructure development. Recent research has focused on designing and implementing WATIs at community colleges. Though these studies are limited, they support this study's recommendations for the adoption of technology as a relatively inexpensive and convenient cessation effort and have proven to be effective in helping students to quit ${ }^{25,37-38}$.

Related to both quitline and web-assisted interventions for any target population is the method of referral, which can directly involve existing health and wellness centers at community colleges with trained staff. As with any healthcare setting, champions at the "point of care" can institute and/ or improve their procedures for screening for tobacco use and efficiently refer smokers to adjunctive treatments (these technology-assisted treatments, local area resources, and/or on-site resources such as one-on-one counseling). Two of the four campuses in the present study, for example, had health/ wellness centers consisting of nurses who were previously trained in brief office intervention for tobacco use (and which included the New York State Quitline and Quitsite as referral options for smokers).

Another potentially feasible approach is the opportunity for community colleges to partner with community organizations and health agencies. By developing these partnerships, community colleges are able to expand their available resources, collaborate with health experts, and promote cessation efforts with a variety of consistent and complementary strategies - 
with the goal of increasing the likelihood of tobacco prevention and cessation amongst students $\mathrm{s}^{35}$. As observed in the present study, for example, the American Cancer Society (ACS) had a noticeable collaborative relationship with each of the campuses, including partnerships with the health/wellness centers, the presence of a variety of ACS materials regarding tobacco cessation and other health issues (brochures, pamphlets), and messaging regarding annual partnered events such as "Relay for Life", where the students are encouraged to sponsor teams and events.

The study has several limitations. As is typical with qualitative methods where quantitative "generalizability" is not the objective, the findings nevertheless reflect the perspectives of a relatively small number of participants. Although it was possible to obtain practical data to provide greater understanding of the context of community college campuses in relation to tobacco control efforts, the level of consistency in themes across campuses and qualitative data sources may have been influenced by over-represented perspectives such as multiple quotes from the same individuals.

\section{CONCLUSION}

This study provides an examination of attitudes, policies, and practices regarding tobacco control at community colleges. Though limited to four colleges, this analysis identified a number of common themes across campuses. Tobacco control policies, while often present, need the support of increased adherence and enforcement. Tobacco control initiatives can currently be improved without requiring additional or costly resources for infrastructure or staff. Cessation interventions must be convenient, easy to understand, and accessible from multiple locations. Screening, treatment and referral (e.g., by onsite health/wellness center health care providers) is a recommended proactive approach. Technology assisted strategies, such as quitlines and web-based resources, are recommended approaches consistent with the findings of the present study. Results of the present study provide initial guidance for new research and new interventions for this growing but understudied and underserved population.

\section{REFERENCES}

1. Aud, S., Hussar, W., Johnson, F., Kena, G., Roth, E., Manning, E., Wang, X., and Zhang, J. The Condition of Education (NCES 2012-045). U.S. Department of Education, National Center for Education Statistics. 2012 Washington, DC. Available from: http:// nces.ed.gov/pubsearch/pubsinfo.asp?pubid=2012045. (accessed August 2016)

2. VanKim, N. A., Laska, M. N., Ehlinger, E., Lust, K., \& Story, M. Understanding young adult physical activity, alcohol and tobacco use in community colleges and 4-year post-secondary institutions: A cross-sectional analysis of epidemiological surveillance data. BMC
Public Health 2010, 10(1):208.

DOI: $10.1186 / 1471-2458-10-208$

3. Emmons, K. M., Wechsler, H., Dowdall, G., \& Abraham, M. Predictors of smoking among US college students. American Journal of Public Health 1998, 88(1):104-107.

4. Rigotti, N. A., Lee, J. E., \& Wechsler, H. US college students' use of tobacco products. Journal of the American Medical Association 2000, 284(6): 699-705.

DOI:10.1001/jama.284.6.699.

5. King B, Dube S, Kaufmann R, Shaw L, Pechacek T. Vital Signs: Current Cigarette Smoking Among Adults Aged $>=18$ YearsUnited States, 2005-2010 (Reprinted from MMWR, vol 60, pg 1207-1212, 2011). Journal of The American Medical Association 2011 Nov 2;306(17):1857-60.

6. Berg C.J, An L.C., Thomas J.L., Lust K., Sanem J.R., Swan D.W., Ahluwalia, J.S. Smoking patterns, attitudes, and motives among two-year college and four-year college students. Health Education Research 2011, 26(4):614-623. DOI:10.1093/her/cyr017.

7. Lenk KM, Erickson DJ, Nelson TF, Winters KC, Toomey TL. Alcohol Policies and Practices Among Four-Year Colleges in the United States: Prevalence and Patterns. Journal of Studies on Alcohol and Drugs 2012, 73(3): 361-367.

DOI: $10.15288 /$ jsad.2012.73.361

8. Butler, K. M., Fallin, A., \& Ridner, S. L. Evidence-based smoking cessation for college students. The Nursing Clinics of North America 2012, 47(1), 21-30. DOI:10.1016/j.cnur.2011.10.007

9. Nichter, M., Nichter, M., Carkoglu, A., \& Tobacco Etiology Research Network. Reconsidering stress and smoking: A qualitative study among college students. Tobacco Control 2007, 16(3): 211-214. DOI:10.1136/tc.2007.019869

10. Pierceall, E.A., Keim, M.C. Stress and coping strategies among community college students. Community College Journal of Research and Practice 2007, 31(9): 703-712.

DOI: $10.1080 / 10668920600866579$

11. Mokdad, A. H., Marks, J. S., Stroup, D. F., \& Gerberding, J. L. Actual causes of death in the United States, 2000. Journal of the American Medical Association 2004, 291(10): 1238-1245.

DOI:10.1001/jama.291.10.1238.

12. United States Department of Health and Human Services Office of Disease Prevention and Health Promotion. (2016). Healthy people 2020. Available from https://www.healthypeople.gov/2020/topicsobjectives/objective/ecbp-75 (accessed August 2016)

13. American College Health Association. (2011). ACHA guidelines: Position statement on tobacco on college and university campuses. Linthicum, MD. Available from https://www.acha.org/documents/ resources/guidelines/ACHA_Position_Statement_on_Tobacco_ Nov2011.pdf (accessed August 2016)

14. Floyd, D. L. Student health: Challenges for community colleges. Community College Journal of Research \& Practice 2003, 27(1): 25-39.

DOI: $10.1080 / 713838081$

15. Bragg, D. D. (2001). Community college access, mission, and outcomes: Considering intriguing intersections and challenges. Peabody Journal of Education 2001, 76(1):93-116. DOI: 10.1207/S15327930PJE7601_06

16. Cohen, A. M., Brawer, F. B. The American Community College (5th Edition) 2008. San Francisco, CA: Jossey-Bass.

17. Aud, S., Wilkinson-Flicker, S., Kristapovich, P., Rathbun, A., Wang, X., and Zhang, J. The Condition of Education. 2013 (NCES 2013037). U.S. Department of Education, National Center for Education Statistics. Washington, DC. Available from http://nces.ed.gov/ 
pubsearch/pubsinfo.asp?pubid=2013037. (accessed August 2016)

18. Bailey, T., Jenkins, D., \& Leinbach, T. What we know about community college low-income and minority student outcomes: Descriptive statistics from national surveys. 2005. New York, NY: Columbia University, Teachers College, Community College Research Center. Available from http://files.eric.ed.gov/fulltext/ ED484354.pdf (accessed August 2016)

19. Pokhrel, P., Little, M.A., Herzog, T.A. Current Methods in Health Behavior Research Among U.S. Community College Students: A Review of the Literature. Evaluation \& the Health Professions 2014, 37(2) 178-202.

DOI: $10.1177 / 0163278713512125$

20. Sanem, J. R., Berg, C.J., An, L.C., Kirch, M.A., \& Lust, K.A. Differences in tobacco use among two-year and four-year college students in Minnesota. Journal of American College Health 2009, 58(2): 151-159.

DOI: $10.1080 / 07448480903221376$

21. James, D.C.S., Chen, W.W., \& Sheu, J.J. Type of tobacco product used: Are there differences between university and community college students? Journal of Drug Education 2007, 37(4), 379-392. DOI: 10.2190/DE.37.4.b

22. Berg, C.J., Lessard, L., Parelkar, P.P., Thrasher, J., Kegler, M.C., Escoffery, C., Goldade, K, Ahluwalia, J. S. College student reactions to smoking bans in public, on campus and at home. Health Education Research 2011, 26(1): 106-118.

DOI:10.1093/her/cyq076

23. Prokhorov, A.V., Warneke, C., de Moor, C., Emmons, K.M., Mullin Jones, M., Rosenblum, C., Suchanek Hudmon, K., Gritz, E.R.. Selfreported health status, health vulnerability, and smoking behavior in college students: Implications for intervention. Nicotine \& Tobacco Research : Official Journal of the Society for Research on Nicotine and Tobacco 2003, 5(4), 545-552.

DOI: $10.1080 / 1462220031000118649$

24. Ottenritter, N. National Study on Community College Health. Community College Press, American Association of Community Colleges 2002, Washington, DC. ERIC Number: ED464663

25. Prokhorov, A.V., Yost, T., Jones, M.M., de Moor, C., Ford, K.H., Marani, S., Kilfoy, B.A., Hein, J.P., Suchanek Hudmon, K., Emmons, K.M. "Look at your health": Outcomes associated with a computerassisted smoking cessation counseling intervention for community college students. Addictive Behaviors 2008, 33(6):757.

DOI:10.1016/j.addbeh.2007.12.005

26. Hasman, L., Berryman, D., \& McIntosh, S. NLM Informationist Grant - Web Assisted Tobacco Intervention for Community College Students 2013. Journal of eScience Librarianship, 2(1): Article 8. DOI: $10.7191 /$ jeslib.2013.1034

27. Creswell, J. Educational research: Planning, conducting, and evaluating quantitative and qualitative research 2002. Saddle River, NJ: Prentice Hall.

28. Strauss, A., Corbin, J. Basics of qualitative research: Techniques and procedures for developing grounded theory (3rd Edition) 2007. Thousand Oaks, CA: Sage Publications, Incorporated.

29. Guba, E. G., \& Lincoln, Y. S. Naturalistic inquiry 1985. Vol 75. Thousand Oaks, CA: Sage Publications, Incorporated.

30. Murphy-Hoefer, R., Griffith, R., Pederson, L. L., Crossett, L., Iyer, S. R., \& Hiller, M. D. A review of interventions to reduce tobacco use in colleges and universities. American Journal of Preventive Medicine 2005, 28(2): 188-200.

DOI:10.1016/j.amepre.2004.10.015

31. Cummins, S. E., Hebert, K. K., Anderson, C. M., Mills, J. A., \& Zhu, S. Reaching young adult smokers through quitlines. American Journal of Public Health 2007, 97(8): 1354-1356.
DOI: 10.2105/AJPH.2006.101741

32. Ossip-Klein, D.J., McIntosh, S. Quitlines in North America: Evidence base and applications. American Journal of the Medical Sciences 2003, 326(4): 201-205.

DOI: $10.1097 / 00000441-200310000-00010$

33. Sims, T.H., McAfee, T., Fraser, D.L., Baker, T.B., Fiore, M.C., Smith, S.S. Quitline cessation counseling for young adult smokers: A randomized clinical trial. Nicotine \& Tobacco Research 2013, 15(5), 932-941.

DOI: $10.1093 / \mathrm{ntr} / \mathrm{nts} 227$

34. Norman, C. D., McIntosh, S., Selby, P., Eysenbach, G. Web-assisted tobacco interventions: Empowering change in the global fight for the public's (e)health. Journal of Medical Internet Research 2008, 10(5); $\mathrm{e} 28$.

DOI: $10.2196 /$ jmir.1171

35. Wall, A. F., BaileyShea, C., \& McIntosh, S. Community college student alcohol use developing context-specific evidence and prevention approaches. Community College Review 2012, 40(1): $25-45$.

DOI: $10.1177 / 0091552112437757$

36. Stearns, M., Nambiar, S., Nikolaev, A., Semenov, A., McIntosh, S. (2014). Towards Evaluating and Enhancing the Reach of Online Health Forums as a Treatment of Smoking. Network Modeling and Analysis in Health Informatics \& Bioinformatics 2014, 3(1):1-11. DOI:10.1007/s13721-014-0069-7.

37. Donovan, E., Chiauzzi, E., Floyd, D. L., Bond, K., \& Wood, M. The feasibility of an online health program for community college students. Community College Journal of Research and Practice 2012, 36(9): 637-655.

DOI: $0.1080 / 15363759.2011 .559886$

38. Prokhorov, A.V., Fouladi, R.T., de Moor, C., Warneke, C. L., Luca, M., Jones, M.M., Rosenblum, C., Emmons, K.M., Suchanek Hudmon, K., Yost., T.E., Gritz, E.R. Computer-assisted, counselordelivered smoking cessation counseling for community college students: Intervention approach and sample characteristics. Journal of Child \& Adolescent Substance Abuse 2007, 16(3): 35-62. DOI: 10.1300/J029v16n03_03
The authors would like to thank all Community College participants who shared their time and opinions, and Ms. Hollis Colburn for assistance with transcription

\section{CONFLICT OF INTEREST}

The authors have completed and submitted the ICMJE Form for Disclosure of Potential Conflicts of Interest and none were reported.

\section{FUNDING}

This work was supported by the National Cancer Institute (RO1CA152093$01)$. Its contents are solely the responsibility necessarily represent the official views of the National Cancer Institute or the National Institutes of Health.

PROVENANCE AND PEER REVIEW

Not commissioned; externally peer reviewed.

\section{ACKNOWLEDGEMENTS} of the authors and do not 